\title{
Modified Delphi-AHP Method Based on Minimum-Cost Consensus Model and Vague Set Theory for Road Junction Control Method Evaluation Criteria Selection
}

\author{
P. K. Kwok and Henry Y. K. Lau \\ Department of Industrial and Manufacturing Systems Engineering \\ The University of Hong Kong, Pokfulam, Hong Kong \\ Email: \{kwokalex, hyklau\}@hku.hk
}

\begin{abstract}
Group decision making is an important symbol of a democratic society. It helps to explore problems from wider angles and the results generated will usually be widely accepted by the public. Yet, there are drawbacks of group decision making. It usually takes more time and resources than individual decision making and also sometimes the one with a louder voice will dominate the discussion. In this paper, a group decision making framework derived that are based on the modified Delphi-AHP method based on minimum-cost consensus model (MCCM) and vague set theory is proposed to gather different experts' opinions on the evaluation criteria and their relative importance for choosing a suitable road junction control method in a multiobjectives environment. It is believed that the proposed framework can help to strengthen the advantages and to solve the above drawbacks of group decision making. A numerical case study is proposed to demonstrate the use of this framework.
\end{abstract}

Index Terms-group decision making, delphi method, analytic hierarchy process (AHP), minimum-cost consensus model, vague set theory, optimization.

\section{INTRODUCTION}

Choosing a proper road junction control (RJC) method, e.g. signalized intersection, roundabout and interchange, is not an easy task as many conflicting factors (criteria) need to be considered e.g. cost vs. efficiency. Kwok, Chau and Lau [1] has accounted for the importance in choosing a proper RJC method and proposed a fuzzy TOPSIS multi-criteria decision making framework to facilitate the selection process on contradicting criteria. However, like most of the papers presenting TOPSIS method e.g. [2] and [3], less focus has been put on how the criteria and their importance weight are obtained - a group decision making problem.

Public consultation and group decision making are crucial for government construction projects in a democratic society. It can help to look into the problems from different angles and most importantly make a final decision that will more likely to be accepted by the public.

Manuscript received March 5, 2015; revised May 26, 2015.
However, compromising the experts' decision is challenging. Take the road junction construction project as an example: usually many stakeholders, e.g. civil engineers, environmentalist and residents living nearby are involved and each of them has their own thought and area of concern. Compromising their ideas for TOPSIS analysis is difficult, not mentioning other drawbacks and the huge resources needed in group decision making. Ness and Hoffman [4] has given the following definition to the word 'consensus': "a decision that has been reached when most members of the team agree on a clear option and the few who oppose it think they have had a reasonable opportunity to influence that choice. All team members agree to support the decision".

Hence, in this paper, a group decision making framework with the use of a modified Delphi-AHP method based on MCCM and vague set theory is presented to efficiently account for the group consensus problem in selecting the evaluation criteria for RJC methods selection and to ensure that every participant has a reasonable opportunity to influence the result. This paper is developed into 5 sections: following Section I the introduction, literature reviews to provide the basic knowledge regarding the proposed group decision framework is provided in Section II. The proposed group decision framework is then illustrated in Section III. Section IV then provides a numerical example followed by some discussions to illustrate the proposed framework. Finally, conclusion is drawn in Section V.

\section{LITERATURE REVIEWS}

\section{A. Delphi Method}

Delphi method was initially proposed by the RAND Corporation in $1950 \mathrm{~s}$ to facilitate negotiation and consensus reaching [5]. In general, Delphi method divides a survey process into multiple rounds. In each round, results of the previous round will be provided to the participants so that they can choose whether they would like to alter their decision based on the results in the previous round [6]. The advantage of Delphi method is that it encourages a true debate, i.e. independence of 
personalities [7]. Hence, in the past decades, Delphi method has been widely used in many strategic planning areas like technology foresight and Cuhls [5] claims that Delphi method is useful for planning new things.

An example of research in Delphi method application is reaching consensus on the selection of procurement systems for construction projects [8].

\section{B. The AHP Method}

Analytic Hierarchy Process (AHP) is one of the popular multi-criteria decision making methods proposed by Saaty [9] in 1972 for making complex decisions in multiple conflicting criteria problem. Different from other multi-criteria decision making methods using direct allocation of weights, AHP uses pair-wise comparisons in multi-level hierarchical structures to achieve the decision result. This is the major advantage of AHP. The pair-wise comparisons characteristic of AHP allows decision makers to focus only on specific criteria when giving the ratings, since humans would express their views more easily and accurately when only two alternatives rather than all alternatives are given at the same time [10]. This is the reason why AHP is used here together with Delphi method for experts to facilitate the process of determining the importance of the evaluation criteria for choosing a RJC method. AHP is used to summarize the criteria comparison into weight priority, which will then be the input of importance weight for TOPSIS analysis.

An example of research in AHP application is military's weapon system evaluation [11].

\section{Minimum-Cost Consensus Model}

Minimum-Cost Consensus Model (MCCM) is a rather new concept proposed by Ben-Arieh and Easton [12] in 2007 aiming at minimizing the resources (cost) of reaching consensus. Ben-Arieh, Easton and Evans [13] point out a drawback of group decision making is that it usually requires more time and resources than that of individual decision making, as lots of time and resources are put to influence the experts' opinion. However, not many research have taken the cost of aggregating the experts' opinion into consideration [13]. For government consultation, especially the road junction construction projects, the longer the consultation time, the higher the construction cost is expected to be because construction materials price is growing. Hence, MCCM is used here to calculate the optimal opinion of each expert, where the least number of move from their original opinion is expected, in order to reach the target consensus rate.

Since the proposal of the MCCM, further research by expanding this concept into optimization model with aggregation operators [14] have been done, but few of them have implemented it into the Delphi method.

\section{Vague Set Theory}

Human subjective judgments with preferences are usually vague. Hence, it is important to involve the fuzzy set theory to deal with information involving subjective preference in the decision making process [15]. In mathematical terms, fuzzy sets are sets with degree of membership for their elements $\left(A=\left\{\left\langle u, \mu_{A(u)}\right\rangle \mid u \in U\right\}\right)$.
However, the shortcoming of traditional fuzzy set theory is that the fuzzy set is not really fuzzy in the whole [15], as the evidence for $\mathrm{u} \in \mathrm{U}$ are mixed with the evidence against $\mathrm{u} \in \mathrm{U}$ [16]. Therefore, Gau and Buehrer [17] introduce the notion of vague set theory. In general, a vague set in universe $U$ is formed by a true membership function, $\alpha_{\mathrm{V}} \in \mathrm{U}$ between 0 and 1 , and a false membership function, $\beta_{\mathrm{V}} \in \mathrm{U}$ between 0 and 1 , such that $\alpha_{\mathrm{V}}(\mathrm{u})+\beta_{\mathrm{V}}(\mathrm{u}) \leq 1 \quad[16]$. The interval-based grade of membership nature in vague set theory allows vague set theory to be more expressive in capturing the vagueness of data and hesitation to membership degree than the traditional fuzzy set theory [16]. Noting this advantage, vague set theory is proposed to capture the subjective and vague opinion given by the experts.

With the reasons stated above, in this paper, a modified Delphi-AHP method based on MCCM and vague set theory is presented to demonstrate how MCCM can be implemented in the Delphi method to facilitate the process of reaching a consensus and that vague set theory can be used with Delphi-AHP to capture the hesitation and vagueness of the opinions given by the experts so as to formulate the input of importance weight for the TOPSIS RJC method evaluation process.

\section{METHODOLOGY}

\section{A. Delphi Method to Identify Evaluation Criteria and their Inter-Relative Importance for RJC Method}

1) Preliminary work

Finding the experts: Statistically speaking, the quality and representativeness of the result will be affected by the number and knowledge of the participants, so finding participants with knowledge and interest to the subject is important, so-called the 'experts'. Often, purposive sampling or criterion sampling strategy is used for sampling the experts [18]. Luckily, sampling experts for projects relating to government or public issues is easier as the stakeholders will automatically show up and express their opinions in the consultation period. Since they are usually the individuals affected by the construction tasks directly e.g. residents nearby and district councils or the groups with particular area of concerns e.g. green groups, they should have enough knowledge about and interest in the subject and can be counted as experts for the Delphi decision making.

Grouping the experts: After the experts are invited/ identified, the steering committee should group the experts according to their nature. This act helps to balance the bargaining power of each group of experts in later stage and generate a more accurate and reliable decision-making model.

\section{2) The delphi process}

Theoretically, Delphi method divides the evaluation process into several rounds and there is no limit on how many rounds the Delphi process should be divided. It just depends on the amount of time and resources available. The proposed framework is divided into 3 rounds.

Round 1: Delphi process often start with an openended set of questions, allowing the participants a 
complete freedom to express themselves, so as to explore general ideas to the topic [6]. Open-ended questions like "What criteria do you think are needed to be taken into account when considering which RJC method should be chosen?" After getting the response from the participants, the steering committee should summarize the information collected, grouping similar criterion together and using the information to construct the questionnaire for the next round survey. Although Hasson, Keeney and McKenna [18] suggest some researchers claimed that some infrequently occurred criterion can be removed from the summary so as to keep the result list clean, they conclude that that approach goes against the purpose of Delphi method that the quality of items should be judged by the participants rather than the steering committee.

Round 2: Each expert receives a questionnaire constructed by summarizing the opinions by the steering committee in Round 1. They will be asked to review the summary of the information given in Round 1 and then compare and rate the importance of the evaluation criteria summarized in Round 1 and write down their reasons.

In most of the Delphi research, the rating process is done in crisp value. However, human subjective decisions including preference are usually vague and fuzzy rather than crisp. Hence, vague set theory should be included to account for these uncertainties and fuzziness.

To enable the use of vague set theory for capturing hesitation and uncertainty and AHP pair-wise comparison for ranking the evaluation criteria's importance in afterwards, the following questions can be asked. (For simplicity reason, this paper does not take the question wordings into consideration.)

i. How much more importance do you think Criterion $\mathrm{A}$ is when comparing to Criterion $\mathrm{B}$ ?*

ii. How much more importance do you think Criterion $\mathrm{B}$ is when comparing to Criterion A?*

iii. How confident are you for the above answers?\#

iv. Explain your reason(s).

* Scale in Table I is used.

\#Simple 1-10 scale is used. (10 is the most confident.)

TABLE I. DEFinition of ScAle VALue for PAiR-Wise COMPARISON

\begin{tabular}{|c|l|}
\hline Scale & \multicolumn{1}{c|}{ Definition } \\
\hline 0.0 & No comparable can be made \\
\hline 0.1 & Criteria A is 'not important' than Criteria B \\
\hline 0.3 & Criteria A is 'less important' than Criteria B \\
\hline 0.5 & Criteria A is 'equal important' than Criteria B \\
\hline 0.7 & Criteria A is 'more important' than Criteria B \\
\hline 0.9 & Criteria A is 'very important' than Criteria B \\
\hline $0.2,0.4,0.6,0.8$ & The importance values in between of above odd numbers \\
\hline
\end{tabular}

Suppose $V=\left[\alpha_{\mathrm{V}}\left(\mathrm{u}_{\mathrm{i}}\right), 1-\beta_{\mathrm{V}}\left(\mathrm{u}_{\mathrm{i}}\right)\right]$ is a vague set in universe $\mathrm{U}=\left\{\mathrm{u}_{1}, \mathrm{u}_{2}, \ldots, \mathrm{u}_{\mathrm{n}}\right\}$ capturing the importance of Criterion $\mathrm{A}$ on top of Criterion B. The aim of question (i) is to understand to what extent an expert agrees that Criterion $\mathrm{A}$ is superior than Criterion B in order to capture the level of true membership $\alpha$ in vague set $\mathrm{V}$, while the aim of question (ii) is to understand to what extent the same expert disagrees that Criterion $\mathrm{A}$ is superior than Criterion $\mathrm{B}$ in order to capture the level of false membership $\beta$ in vague set $V$. It is not necessary for $\alpha=$ $1-\beta$. The hesitation level of the expert on a certain subject can be calculated with $\delta_{\mathrm{V}}\left(\mathrm{u}_{\mathrm{i}}\right)=1-\beta_{\mathrm{V}}\left(\mathrm{u}_{\mathrm{i}}\right)-\alpha_{\mathrm{V}}\left(\mathrm{u}_{\mathrm{i}}\right)$. The higher the $\delta$ value, the more affirmative their answers are, and vice versa [16]. The aim of question (iii) is to know how confident the expert is to his answers. Usually, the more confident he is, the more difficult to change his opinion and hence more resources (time and cost) are needed in order to persuade him to alter his opinion by 1 unit. Question (iii) is essential in order to build MCCM.

After collecting the responses from the experts, the steering committee is again required to summarize the responses and prepare for the questionnaire for the next round survey. In order to provide some guidance and direction of changes to the experts in Round 3 to reach the targeted consensus level with fewer resources and time, the following modified MCCM is adopted to aggregate the opinions in Round 2 and calculate the suggested opinions for Round 3 survey:

Notations - Denote the following notations:

$\mathrm{E}_{\mathrm{j}}$ : The number of experts belonging to group $\mathrm{j}$ determined in the preliminary work

$\mathrm{E}$ : The total number of experts

$\mathrm{N}$ : The total number of groups of experts divided in the preliminary work

$\mathrm{M}=\mathrm{C}(\mathrm{m}, 2)$ : The total number of criteria comparison sets, where $m$ is the total number of criteria summarized in Delphi process Round 1

$\tilde{\mathrm{e}}_{\mathrm{ijk}}=\left[\alpha_{\mathrm{ijk}}, 1-\beta_{\mathrm{ijk}}\right]$ : The original opinion of expert $\mathrm{i}$ in group $\mathrm{j}$ for criteria comparison set $\mathrm{k}$

$\tilde{\mathrm{e}}_{\mathrm{ijk}}{ }^{\prime}=\left[\alpha_{\mathrm{ijk}}, 1-\beta_{\mathrm{ijk}}{ }^{\prime}\right]$ : The altered opinion of expert $\mathrm{i}$ in group $\mathrm{j}$ for criteria comparison set $\mathrm{k}$

$\tilde{\mathrm{o}}_{\mathrm{jk}}=\left[\bar{\alpha}_{\mathrm{jk}}, 1-\beta_{\mathrm{jk}}\right]$ : The original aggregated opinion of group $\mathrm{j}$ for criteria comparison set $\mathrm{k}$, such that:

$$
\tilde{o}_{j k}=\sum_{i=1}^{E_{j}} r_{i j k} \tilde{e}_{i j k}
$$

$\tilde{\mathrm{o}}_{\mathrm{jk}}{ }^{\prime}=\left[\bar{\alpha}_{\mathrm{jk}}, 1-\beta_{\mathrm{jk}}{ }^{\prime}\right]:$ The altered aggregated opinion of group $\mathrm{j}$ for criteria comparison set $\mathrm{k}$

$\delta_{\mathrm{kT}}$ : The threshold hesitation level defined by the steering committee for criteria comparison set $\mathrm{k}$ for all groups and experts

$v_{\mathrm{kT}}$ : The targeted consensus level defined by the steering committee for criteria comparison set $\mathrm{k}$ of the groups and within the groups

$\mathrm{r}_{\mathrm{ijk}}$ : The subjective weight assigned to each expert $\mathrm{i}$ in group $\mathrm{j}$ by the steering committee for criteria comparison $\mathrm{k}$, in order to balance the negotiation power of the experts, such that:

$$
\sum_{i=1}^{E_{j}} r_{i j k}=1
$$

$\mathrm{w}_{\mathrm{jk}}$ : The subjective weight assigned to group $\mathrm{j}$ by the steering committee for criteria comparison $\mathrm{k}$, in order to balance the negotiation power of the groups, such that:

$$
\sum_{j=1}^{N} w_{j k}=1
$$

$\omega_{\mathrm{jk}}$ : The overall importance weight for group $\mathrm{j}$ for criteria comparison set $\mathrm{k}$, such that: 


$$
\omega_{j k}=\gamma w_{j k}+(1-\gamma) E_{j} / E
$$

$\gamma$ : The relaxation factor between 0 and 1 for calculating $\omega_{\mathrm{jk}}$

$f_{i j k}$ : The confident rate given by expert $\mathrm{i}$ in group $\mathrm{j}$ for criteria comparison set $\mathrm{k}$ in question (iii)

$f_{i j k}\left[D\left(\tilde{e}_{i j k}, \tilde{e}_{i j k}\right)\right]^{2}$ : The cost function of expert $\mathrm{i}$ in group $\mathrm{j}$ to alter his opinion for criteria comparison set $\mathrm{k}$ from $\tilde{\mathrm{e}}_{\mathrm{ijk}}$ to $\tilde{\mathrm{e}}_{\mathrm{ijk}}$ '. (Negotiation cost is often quadratic [13].)

$c_{j k}$ : The summation of the confident rate given by the experts in group $\mathrm{j}$ for criteria comparison set $\mathrm{k}$ in question (iii), such that:

$$
c_{j k}=\sum_{i=1}^{E_{j}} f_{i j k}
$$

$c_{j k}\left[D\left(\tilde{o}_{j k}, \tilde{o}_{j k}\right)\right]^{2}$ : The cost function of group $\mathrm{j}$ to alter its opinion for criteria comparison set $\mathrm{k}$ from $\tilde{\mathrm{o}}_{\mathrm{jk}}$ to $\tilde{\mathrm{o}}_{\mathrm{jk}}$,

Notations - Denote the following functions:

Let $\tilde{a}$ and $\tilde{b}$ be two vague values such that $\tilde{a}=\left[\alpha^{\prime}, 1-\beta^{\prime}\right]$ and $\tilde{b}=[\alpha, 1-\beta]$. (6) and (7) are to calculate the difference and similarity of the two vague values respectively:

$$
\begin{gathered}
D(\tilde{a}, \tilde{b})=\left|\alpha^{\prime}-\alpha\right|+\left|\beta^{\prime}-\beta\right| \\
S(\tilde{a}, \tilde{b})=\sqrt{\left[1-\frac{\left|\left(\alpha^{\prime}-\alpha\right)-\left(\beta^{\prime}-\beta\right)\right|}{2}\right]\left[1-\left|\left(\alpha^{\prime}-\alpha\right)+\left(\beta^{\prime}-\beta\right)\right|\right]}
\end{gathered}
$$

Step 1 - Group the experts' opinion: Aggregate the experts' opinions and cost with (1) and (5) to get $\tilde{o}_{j k}$ and $\mathrm{c}_{\mathrm{jk}}$ respectively.

Step 2 - Find the optimal points for reaching the targeted overall consensus rate: Negotiation cost is often quadratic [13]. Quadratic programming (8) is used to calculate the optimal opinions that the groups are suggested to move to in order to reach the targeted overall consensus rate for criteria comparison set $\mathrm{k}$ : $\mathrm{v}_{\mathrm{kT}}$.

$$
\begin{aligned}
& \min \sum_{k=1}^{M} \sum_{j=1}^{N} \omega_{j k} c_{j k}\left[D\left(\tilde{o}_{j k}{ }^{\prime}, \tilde{o}_{j k}\right)\right]^{2} \\
& \text { s.t. }\left\{\begin{array}{l}
\frac{1}{N} \sum_{j=1}^{N}\left[\frac{1}{N-1} \sum_{\substack{v=1 \\
v \neq j}}^{N} S\left(\tilde{o}_{j k}{ }^{\prime}, \tilde{o}_{v k}{ }^{\prime}\right)\right] \geq v_{k T} \\
0 \leq 1-\bar{\beta}_{j k}{ }^{\prime}-\bar{\alpha}_{j k}{ }^{\prime} \leq \delta_{k T} \\
\tilde{o}_{j k}{ }^{\prime} \geq 0, \quad \tilde{o}_{j k} \geq 0 \\
j=1,2, \ldots, N, \quad k=1,2, \ldots, M
\end{array}\right.
\end{aligned}
$$

Step 3 - Find the optimal points for reaching the targeted consensus rate for each group: After the optimal opinions for group $\mathrm{j}$ for criteria comparison set $\mathrm{k}$ is determined, say $\tilde{\mathrm{o}}_{\mathrm{jk}}{ }^{*}=\left[\bar{\alpha}_{\mathrm{jk}}{ }^{*}, 1-\beta_{\mathrm{jk}}{ }^{*}\right]$, another quadratic programming (9) is run for each group to determine the optimal opinions for each expert in order to reach the targeted consensus rate for criteria comparison set $\mathrm{k}$ : $\mathrm{v}_{\mathrm{kT}}$ within the group.

$$
\begin{aligned}
& \min \sum_{k=1}^{M} \sum_{i=1}^{E_{j}} r_{i j k} f_{i j k}\left[D\left(\tilde{e}_{i j k}{ }^{\prime}, \tilde{e}_{i j k}\right)\right]^{2} \\
& \text { s.t. }\left\{\begin{array}{l}
\frac{1}{E_{j}} \sum_{i=1}^{E_{j}}\left[\frac{1}{E_{j}-1} \sum_{\substack{v=1 \\
v \neq i}}^{E_{j}} S\left(\tilde{e}_{i j k}{ }^{\prime}, \tilde{e}_{v j k}{ }^{\prime}\right)\right] \geq v_{k T} \\
\sum_{i=1}^{E_{j}} r_{i j k} \tilde{e}_{i j k}{ }^{\prime}=\tilde{o}_{j k}^{*} \\
0 \leq 1-\beta_{i j k}{ }^{\prime}-\alpha_{i j k}{ }^{\prime} \leq \delta_{k T} \\
\tilde{e}_{i j k}{ }^{\prime} \geq 0, \quad \tilde{e}_{i j k} \geq 0 \\
i=1,2, \ldots, E_{j}, \quad j=1,2, \ldots, N, \quad k=1,2, \ldots, M
\end{array}\right.
\end{aligned}
$$

By solving (9), optimal opinions $\tilde{\mathrm{e}}_{\mathrm{ijk}}{ }^{*}=\left[\alpha_{\mathrm{ijk}}{ }^{*}, 1-\beta_{\mathrm{ijk}}{ }^{*}\right]$ for each expert should be determined. These are the targeted opinions that the experts are expected to move to (at least) in Round 3 in order to make the overall consensus rate reaches $v_{\mathrm{kT}}$.

Round 3: Each expert receives a questionnaire which summarizes the ratings and views of all participants in Round 2 and their suggested opinions $\left(\tilde{\mathrm{e}}_{\mathrm{ijk}}{ }^{*}\right)$ as reference. They will then be provided an opportunity to alter their judgments based on their reviews and opinions for the summary of Round 2. More Delphi iterations by repeating Round 3 and updating $\tilde{\mathrm{e}}_{\mathrm{ijk}}{ }^{*}$ can be carried out if the consensus on certain subject is still very little.

\section{B. AHP to Find the Relative Importance of the Criteria}

Step 1 - Construct comparison matrix for AHP: After reaching a consensus on the inter-relative importance of the evaluation criteria pair in the Delphi process, matrix $\mathrm{A}$ is built like (11) provided there are $\mathrm{m}$ evaluation criteria, with $\tilde{a}_{\mathrm{pq}}$ indicating how much more or less important criterion $\mathrm{p}$ is relative to criterion $\mathrm{q}$ in criteria comparison set $\mathrm{k}$ as calculated by (10). $\tilde{\mathrm{o}}_{\mathrm{jk}}^{\mathrm{C}}$ is the consented opinion of group $\mathrm{j}$ for criteria comparison set $\mathrm{k}$.

$$
\tilde{a}_{p q}=\sum_{j=1}^{N} \omega_{j k} \widetilde{o}_{j k}^{C}
$$

$$
\begin{gathered}
A=\left[\begin{array}{cccc}
\tilde{a}_{11} & \tilde{a}_{12} & \cdots & \tilde{a}_{1 m} \\
\tilde{a}_{21} & \tilde{a}_{22} & \cdots & \tilde{a}_{2 m} \\
\vdots & \vdots & \ddots & \vdots \\
\tilde{a}_{m 1} & \tilde{a}_{m 2} & \cdots & \tilde{a}_{m m}
\end{array}\right]= \\
{\left[\begin{array}{cccc}
{[0.0,1.0]} & {\left[\alpha_{12}, 1-\beta_{12}\right]} & \cdots & {\left[\alpha_{1 m}, 1-\beta_{1 m}\right]} \\
{\left[\alpha_{21}, 1-\beta_{21}\right]} & {[0.0,1.0]} & \cdots & {\left[\alpha_{2 m}, 1-\beta_{2 m}\right]} \\
\vdots & \vdots & \ddots & \vdots \\
{\left[\alpha_{m 1}, 1-\beta_{m 1}\right]} & {\left[\alpha_{m 2}, 1-\beta_{m 2}\right]} & \cdots & {[0.0,1.0]}
\end{array}\right]}
\end{gathered}
$$

where $\alpha_{\mathrm{qp}}=\beta_{\mathrm{pq}}$ and $\beta_{\mathrm{qp}}=\alpha_{\mathrm{pq}}$

In common practice, many research assign the central comparison $\left(\tilde{a}_{\mathrm{pq}}\right.$ for $\left.\mathrm{p}=\mathrm{q}\right)$ to be $[0.5,0.5]$ on $0.1-0.9$ scale. However, from the likelihood view, the expression of vague set $[0.5,0.5]$ can be interpreted as $50 \%$ of a given population agrees that a criterion is more important than itself while another $50 \%$ disagree, which is not the true case. Hence, in the proposed AHP algorithm, it is more rational to assign the central comparison value to be $[0.0,1.0]$ i.e. $\alpha=0, \beta=0$. The vague value $[0.0,1.0]$ can be interpreted as there is not enough information to make comparison on the corresponding object because it is inapplicable to compare with the same criteria [16].

Step 2 - Compute the weights priority for each criterion: Having constructed the comparison matrix A, the weights priority (Eigen vectors) is constructed using the (12). As a remark, Belton and Gear normalization method is used here to avoid rank reversal among the vague set values [19].

$$
\tilde{w}_{p}=\frac{1}{m} \sum_{q=1}^{m} \frac{\tilde{a}_{p q}}{\max _{h \in\{1, \ldots, m\}}\left\{\tilde{a}_{h q}\right\}}
$$

The value of weight priority $\tilde{\mathrm{w}}_{\mathrm{p}}$ shows the relative weight (importance) among the criteria compared. Hence, 
they can be an objective input as the importance weights of the criteria for the TOPSIS analysis for choosing the suitable RJC method.

\section{NUMERICAL EXAMPLE AND DISSCUSSIONS}

\section{A. Numerical Example}

Supposed there are only 9 experts in 3 groups participating in the survey and assumed that only 3 criteria namely delay time, capital cost and safety are suggested in Round 1 of the Delphi process and retained for Round 2 survey. Suppose the relaxation factor $(\gamma)$ for calculating $\omega_{\mathrm{jk}}$ is 0.2 , the targeted consensus level $\left(v_{\mathrm{kT}}\right)$ defined by the project committee for all criteria comparison sets for all groups and experts is $90 \%$ and the threshold hesitation level $\left(\delta_{\mathrm{kT}}\right)$ defined by the project committee for all criteria comparison sets for all groups and experts is 0.3. Assumed the original experts' opinions $\left(\tilde{e}_{i j k}\right)$, their corresponding weights $\left(r_{i j k}\right)$ and costs $\left(f_{k i j}\right)$ and the initial consensus rates of the groups are as shown in Table II and III respectively.

TABLE II. ORIGINAL EXPERTS' OPINION AND THEIR CORRESPONDING WEIGHT AND COST

\begin{tabular}{|c|c|c|c|c|c|}
\hline Expert & Criteria Comparison & $\alpha_{\mathrm{ijk}}$ & $\beta_{\mathrm{ijk}}$ & $r_{i j k}$ & $f_{i j k}$ \\
\hline \multirow{3}{*}{$\begin{array}{l}\text { Group } 1 \\
\text { Expert } 1\end{array}$} & Delay Time to Capital Cost & 0.6 & 0.3 & 0.5 & 8 \\
\hline & Delay Time to Safety & 0.4 & 0.5 & 0.5 & 8 \\
\hline & Capital Cost to Safety & 0.3 & 0.6 & 0.5 & 8 \\
\hline \multirow{3}{*}{$\begin{array}{l}\text { Group } 1 \\
\text { Expert } 2\end{array}$} & Delay Time to Capital Cost & 0.7 & 0.2 & 0.3 & 5 \\
\hline & Delay Time to Safety & 0.3 & 0.6 & 0.3 & 5 \\
\hline & Capital Cost to Safety & 0.3 & 0.7 & 0.3 & 5 \\
\hline \multirow{3}{*}{$\begin{array}{l}\text { Group } 1 \\
\text { Expert } 3\end{array}$} & Delay Time to Capital Cost & 0.6 & 0.4 & 0.2 & 3 \\
\hline & Delay Time to Safety & 0.5 & 0.5 & 0.2 & 3 \\
\hline & Capital Cost to Safety & 0.4 & 0.5 & 0.2 & 3 \\
\hline \multirow{3}{*}{$\begin{array}{l}\text { Group } 2 \\
\text { Expert } 1\end{array}$} & Delay Time to Capital Cost & 0.1 & 0.9 & 0.5 & 8 \\
\hline & Delay Time to Safety & 0.1 & 0.8 & 0.5 & 8 \\
\hline & Capital Cost to Safety & 0.7 & 0.2 & 0.5 & 8 \\
\hline \multirow{3}{*}{$\begin{array}{l}\text { Group } 2 \\
\text { Expert } 2\end{array}$} & Delay Time to Capital Cost & 0.1 & 0.9 & 0.3 & 5 \\
\hline & Delay Time to Safety & 0.2 & 0.7 & 0.3 & 5 \\
\hline & Capital Cost to Safety & 0.6 & 0.4 & 0.3 & 5 \\
\hline \multirow{3}{*}{$\begin{array}{l}\text { Group } 2 \\
\text { Expert } 3\end{array}$} & Delay Time to Capital Cost & 0.2 & 0.8 & 0.2 & 3 \\
\hline & Delay Time to Safety & 0.1 & 0.8 & 0.2 & 3 \\
\hline & Capital Cost to Safety & 0.8 & 0.2 & 0.2 & 3 \\
\hline \multirow{3}{*}{$\begin{array}{l}\text { Group } 3 \\
\text { Expert } 1\end{array}$} & Delay Time to Capital Cost & 0.6 & 0.4 & 0.5 & 8 \\
\hline & Delay Time to Safety & 0.7 & 0.2 & 0.5 & 8 \\
\hline & Capital Cost to Safety & 0.7 & 0.2 & 0.5 & 8 \\
\hline \multirow{3}{*}{$\begin{array}{l}\text { Group } 3 \\
\text { Expert } 2\end{array}$} & Delay Time to Capital Cost & 0.5 & 0.5 & 0.3 & 5 \\
\hline & Delay Time to Safety & 0.6 & 0.2 & 0.3 & 5 \\
\hline & Capital Cost to Safety & 0.8 & 0.2 & 0.3 & 5 \\
\hline \multirow{3}{*}{$\begin{array}{l}\text { Group } 3 \\
\text { Expert } 3\end{array}$} & Delay Time to Capital Cost & 0.6 & 0.4 & 0.2 & 3 \\
\hline & Delay Time to Safety & 0.5 & 0.3 & 0.2 & 3 \\
\hline & Capital Cost to Safety & 0.6 & 0.3 & 0.2 & 3 \\
\hline
\end{tabular}

TABLE III. INITIAL CONSENSUS RATE FOR EACH CRITERIA COMPARISON WITHIN THE GROUPS

\begin{tabular}{|c|l|c|}
\hline Group & \multicolumn{1}{|c|}{ Criteria Comparison } & Consensus Rate \\
\hline Group 1 & Delay Time to Capital Cost & $92 \%$ \\
\cline { 2 - 3 } & Delay Time to Safety & $92 \%$ \\
\cline { 2 - 3 } & Capital Cost to Safety & $92 \%$ \\
\hline \multirow{3}{*}{ Group 2 } & Delay Time to Capital Cost & $97 \%$ \\
\cline { 2 - 3 } & Delay Time to Safety & $97 \%$ \\
\cline { 2 - 3 } & Capital Cost to Safety & $90 \%$ \\
\hline Group 3 & Delay Time to Capital Cost & $97 \%$ \\
\cline { 2 - 3 } & Delay Time to Safety & $92 \%$ \\
\cline { 2 - 3 } & Capital Cost to Safety & $92 \%$ \\
\hline
\end{tabular}

Step 1 - Group the experts' opinion: After grouping experts' opinion, cost and weight using (1), (4) and (5), the aggregated experts' opinions $\left(\tilde{\mathrm{o}}_{\mathrm{jk}}\right)$, weights $\left(\omega_{\mathrm{jk}}\right)$ and costs $\left(c_{j k}\right)$ are shown in Table IV. The initial overall consensus rates for the criteria comparisons are shown in Table V.

TABLE IV. AGgREGATED ORIGINAL EXPERTS' OPINION AND THEIR AGGREGATED WEIGHT AND COST

\begin{tabular}{|c|l|c|c|c|c|}
\hline Expert & \multicolumn{1}{|c|}{ Criteria Comparison } & $\bar{\alpha}_{\mathrm{jk}}$ & $\beta_{\mathrm{jk}}$ & $\omega_{\mathrm{jk}}$ & $\mathrm{c}_{\mathrm{jk}}$ \\
\hline \multirow{3}{*}{ Group 1 1} & Delay Time to Capital Cost & 0.63 & 0.29 & 0.35 & 16 \\
\cline { 2 - 6 } & Delay Time to Safety & 0.39 & 0.53 & 0.35 & 16 \\
\cline { 2 - 6 } & Capital Cost to Safety & 0.32 & 0.61 & 0.35 & 16 \\
\hline \multirow{3}{*}{ Group 2 2} & Delay Time to Capital Cost & 0.12 & 0.88 & 0.35 & 16 \\
\cline { 2 - 6 } & Delay Time to Safety & 0.13 & 0.77 & 0.35 & 16 \\
\cline { 2 - 6 } & Capital Cost to Safety & 0.69 & 0.26 & 0.35 & 16 \\
\hline \multirow{3}{*}{ Group 3 3} & Delay Time to Capital Cost & 0.57 & 0.43 & 0.31 & 16 \\
\cline { 2 - 6 } & Delay Time to Safety & 0.63 & 0.22 & 0.31 & 16 \\
\cline { 2 - 6 } & Capital Cost to Safety & 0.71 & 0.22 & 0.31 & 16 \\
\hline
\end{tabular}

TABLE V. INITIAL OVERALl CONSENSUS RATE FOR EACH CRITERIA COMPARISON AMONG THE GROUPS

\begin{tabular}{|l|c|}
\hline \multicolumn{1}{|c|}{ Criteria Comparison } & Consensus Rate \\
\hline Delay Time to Capital Cost & $76 \%$ \\
\hline Delay Time to Safety & $78 \%$ \\
\hline Capital Cost to Safety & $85 \%$ \\
\hline
\end{tabular}

Step 2 - Find the optimal points for each group for reaching the targeted overall consensus rate: By solving the quadratic programming in (8), the optimal opinions for reaching overall consensus rate of at least $90 \%$ with the least cost for each group $\left(\tilde{\mathrm{o}}_{\mathrm{jk}}{ }^{*}\right)$ are shown in Table VI. The overall consensus rates for the criteria comparisons for the optimal opinions are shown in Table VII.

TABLE VI. OPTIMAL GROUP OPINIONS FOR REACHING 90\% CONSENSUS RATE

\begin{tabular}{|c|l|c|c|}
\hline Group & \multicolumn{1}{|c|}{ Criteria Comparison } & $\bar{\alpha}_{\mathrm{jk}}{ }^{*}$ & $\beta_{\mathrm{jk}}{ }^{*}$ \\
\hline \multirow{4}{*}{ Group 1} & Delay Time to Capital Cost & 0.49 & 0.51 \\
\cline { 2 - 4 } & Delay Time to Safety & 0.31 & 0.39 \\
\cline { 2 - 4 } & Capital Cost to Safety & 0.37 & 0.54 \\
\hline \multirow{3}{*}{ Group 2} & Delay Time to Capital Cost & 0.22 & 0.78 \\
\cline { 2 - 4 } & Delay Time to Safety & 0.14 & 0.56 \\
\cline { 2 - 4 } & Capital Cost to Safety & 0.64 & 0.26 \\
\hline \multirow{3}{*}{ Group 3} & Delay Time to Capital Cost & 0.49 & 0.51 \\
\cline { 2 - 4 } & Delay Time to Safety & 0.42 & 0.28 \\
\cline { 2 - 4 } & Capital Cost to Safety & 0.64 & 0.26 \\
\hline
\end{tabular}

TABLE VII. OVERALl CONSENSUS RATE FOR THE CRITERIA COMPARISONS AFTER OPTIMIZATION AMONG THE GROUPS

\begin{tabular}{|l|c|}
\hline \multicolumn{1}{|c|}{ Criteria Comparison } & Consensus Rate \\
\hline Delay Time to Capital Cost & $90 \%$ \\
\hline Delay Time to Safety & $90 \%$ \\
\hline Capital Cost to Safety & $90 \%$ \\
\hline
\end{tabular}

Step 3 - Find the optimal points for each expert for reaching the targeted consensus rate: After that, the optimal points for reaching consensus rate of at least $90 \%$ within the group with the least cost for each expert $\left(\tilde{\mathrm{e}}_{\mathrm{ijk}}{ }^{*}\right)$ are determined by carrying out another quadratic programming for each group using (9). These are the points going to be reported to the experts in Round 3, suggesting them to change. The results are shown in Table VIII. The consensus rates for the criteria 
comparisons within the groups after optimization are shown in Table VII.

TABLE VIII. OPTIMAL OPINIONS FOR REACHING 90\% CONSENSUS RATE FOR THE EXPERTS

\begin{tabular}{|c|c|c|c|}
\hline Expert & Criteria Comparison & $\alpha_{i j k}{ }^{*}$ & $\beta_{\mathrm{ijk}}{ }^{*}$ \\
\hline \multirow{3}{*}{$\begin{array}{l}\text { Group } 1 \\
\text { Expert } 1\end{array}$} & Delay Time to Capital Cost & 0.53 & 0.47 \\
\hline & Delay Time to Safety & 0.28 & 0.42 \\
\hline & Capital Cost to Safety & 0.33 & 0.55 \\
\hline \multirow{3}{*}{$\begin{array}{l}\text { Group } 1 \\
\text { Expert } 2\end{array}$} & Delay Time to Capital Cost & 0.57 & 0.43 \\
\hline & Delay Time to Safety & 0.28 & 0.42 \\
\hline & Capital Cost to Safety & 0.35 & 0.62 \\
\hline \multirow{3}{*}{$\begin{array}{l}\text { Group } 1 \\
\text { Expert } 3\end{array}$} & Delay Time to Capital Cost & 0.29 & 0.71 \\
\hline & Delay Time to Safety & 0.43 & 0.27 \\
\hline & Capital Cost to Safety & 0.50 & 0.38 \\
\hline \multirow{3}{*}{$\begin{array}{l}\text { Group } 2 \\
\text { Expert } 1\end{array}$} & Delay Time to Capital Cost & 0.16 & 0.84 \\
\hline & Delay Time to Safety & 0.10 & 0.60 \\
\hline & Capital Cost to Safety & 0.66 & 0.20 \\
\hline \multirow{3}{*}{$\begin{array}{l}\text { Group } 2 \\
\text { Expert } 2\end{array}$} & Delay Time to Capital Cost & 0.20 & 0.80 \\
\hline & Delay Time to Safety & 0.20 & 0.50 \\
\hline & Capital Cost to Safety & 0.55 & 0.40 \\
\hline \multirow{3}{*}{$\begin{array}{l}\text { Group } 2 \\
\text { Expert } 3\end{array}$} & Delay Time to Capital Cost & 0.37 & 0.63 \\
\hline & Delay Time to Safety & 0.16 & 0.54 \\
\hline & Capital Cost to Safety & 0.74 & 0.19 \\
\hline \multirow{3}{*}{$\begin{array}{l}\text { Group } 3 \\
\text { Expert } 1\end{array}$} & Delay Time to Capital Cost & 0.55 & 0.45 \\
\hline & Delay Time to Safety & 0.50 & 0.20 \\
\hline & Capital Cost to Safety & 0.64 & 0.22 \\
\hline \multirow{3}{*}{$\begin{array}{l}\text { Group } 3 \\
\text { Expert } 2\end{array}$} & Delay Time to Capital Cost & 0.42 & 0.58 \\
\hline & Delay Time to Safety & 0.42 & 0.28 \\
\hline & Capital Cost to Safety & 0.74 & 0.26 \\
\hline \multirow{3}{*}{$\begin{array}{l}\text { Group } 3 \\
\text { Expert } 3\end{array}$} & Delay Time to Capital Cost & 0.47 & 0.53 \\
\hline & Delay Time to Safety & 0.24 & 0.46 \\
\hline & Capital Cost to Safety & 0.51 & 0.35 \\
\hline
\end{tabular}

TABLE IX. CONSENSUS RATE FOR THE CRITERIA COMPARISON WITHIN THE GROUPS AFTER OPTIMIZATION

\begin{tabular}{|c|l|c|}
\hline Group & \multicolumn{1}{|c|}{ Criteria Comparison } & Consensus Rate \\
\hline Group 1 & Delay Time to Capital Cost & $90 \%$ \\
\cline { 2 - 3 } & Delay Time to Safety & $95 \%$ \\
\cline { 2 - 3 } & Capital Cost to Safety & $90 \%$ \\
\hline Group 2 & Delay Time to Capital Cost & $93 \%$ \\
\cline { 2 - 3 } & Delay Time to Safety & $97 \%$ \\
\cline { 2 - 3 } & Capital Cost to Safety & $90 \%$ \\
\hline Group 3 & Delay Time to Capital Cost & $96 \%$ \\
\cline { 2 - 3 } & Delay Time to Safety & $91 \%$ \\
\cline { 2 - 3 } & Capital Cost to Safety & $90 \%$ \\
\hline
\end{tabular}

Step 4 - AHP Process: Assume that all participants agree to shift their opinions to Table VIII so that the aggregated opinion follows Table VI. The following comparison matrix A is constructed using (10) and (11):

$$
A=\left[\begin{array}{lll}
{[0.00,1.00]} & {[0.40,0.40]} & {[0.29,0.59]} \\
{[0.60,0.60]} & {[0.00,1.00]} & {[0.55,0.65]} \\
{[0.41,0.71]} & {[0.35,0.45]} & {[0.00,1.00]}
\end{array}\right]
$$

After constructing the comparison matrix, the weights priority (Eigen vectors) is calculated using (12), and the results are presented in Table X.

TABLE X. WeIGHT PRIORITY FOR THE EVALUATION CRITERIA

\begin{tabular}{|l|c|}
\hline Evaluation Criteria & Weight Priority $\left(\tilde{\mathrm{w}}_{\mathrm{p}}\right)$ \\
\hline Delay Time & {$[0.51,0.66]$} \\
\hline Capital Cost & {$[0.67,0.75]$} \\
\hline Safety & {$[0.53,0.72]$} \\
\hline
\end{tabular}

These weight priorities are going to form the input of the importance weight of the criteria in the (TOPSIS)
RJC method evaluation process in the later stage, so as to come out the best RJC method.

\section{B. Discussions}

As what can be seen in the model and the numerical example, each participant has an opportunity to influence the result by expressing their opinion in each round of the Delphi method. This suits the definition of consensus by Ness and Hoffman [4].

MCCM is used to calculate the points where the experts' movements and the consensus cost are the least at the same time the targeted consensus levels are reached. In the numerical example, the initial overall consensus rates among the groups based on the experts' original opinion for the 3 criteria comparison sets are only 76 to $85 \%$ (Table V), less than the targeted $90 \%$. After the quadratic programmings, if the optimal points are used, all overall consensus rates reach to at least $90 \%$ (Table VII), although there are some drops in the consensus rate within the groups (Table III v.s. Table IX). However, these drops in consensus rate are acceptable because during consensus making, especially for project consultation, the ultimate goal is not to reach $100 \%$ consensus, but to meet at least the targeted consensus rate.

Also, by considering the results in Table II and Table VIII, it can be seen that less change is suggested to the experts who involve more cost (more confident) and/or are more important. This result make the proposed approach sounds logical. Because for an expert who the steering committee thinks has more knowledge or importance in that particular field, less change in opinion is expected. Also, for an expert who is very confident in his knowledge and opinion, he would not want to change his opinion too much. More resources are needed to persuade him to alter his opinion by one unit.

At the end, AHP is used to summarize the criteria comparisons and rank the importance of the criteria. The value of weight priority represents the aggregated preference of the experts on the importance of the evaluation criteria. Hence, these values is logically be used as the input of importance weight for the TOPSIS analysis for RJC method selection.

\section{CONCLUSION}

In a democratic society, public consultation and group decision making is important as it can help to look into the problems e.g. RJC method selection more deeply, from a wider perspective and make the final decision more likely to be accepted by the general public. However, with the increasing number of stakeholders in a road junction construction plan, group decision making may involve a long period of time and lots of resources. Also, there is a possibility that the group is dominated by the louder voices rather than sound reasons. In this paper, a group decision making framework with the use of a modified Delphi-AHP method based on MCCM and vague set theory is presented to gather the experts' opinions on the evaluation criteria and their relative importance for choosing the most suitable RJC method in a multi-objectives environment. A numerical example has 
been done to demonstrate the use of the framework followed by some discussions to the results.

Further research needs to be done on building a mechanism to ensure the consensus made is a 'good' one which can lead to good influence to the public in long run. Also, more research on question wordings should be studied in order to find out which kind of question wordings is the most suitable.

\section{REFERENCES}

[1] P. K. Kwok, D. W. H. Chau, and H. Y. K. Lau, "A study on road junction control method selection using an artificial intelligent multi-criteria decision making framework," Research and Development in Intelligent Systems, vol. 31, pp. 339-344, 2014.

[2] T. C. Wang and T. H. Chang, "Application of TOPSIS in evaluating initial training aircraft under a fuzzy environment," Expert Systems with Applications, vol. 33, no. 4, pp. 870-880, 2007.

[3] D. Yong, "Plant location selection based on fuzzy TOPSIS," The International Journal of Advanced Manufacturing Technology, vol. 28, no. 7-8, pp. 839-844, 2006.

[4] J. Ness and C. Hoffman, "Putting sense into consensus: Solving the puzzle of making team decisions," VISTA Associates, Tacoma, Wash, 1998.

[5] K. Cuhls, "Delphi method," Fraunhofer Institute for Systems and Innovation Research, Germany, 2003.

[6] C. C. Hsu and B. A. Sandford, "The Delphi technique: making sense of consensus," Practical Assessment, Research \& Evaluation, vol. 12, no. 10, pp. 1-8, 2007.

[7] T. J. Gordon, "The delphi method," Futures Research Methodology, vol. 2, 1994.

[8] A. P. Chan, E. H. Yung, P. T. Lam, C. Tam, and S. Cheung, "Application of delphi method in selection of procurement systems for construction projects," Construction Management \& Economics, vol. 19, no. 7, pp. 699-718, 2001.

[9] T. L. Saaty, "An eigenvalue allocation model for prioritization and planning," Energy Management and Policy Center, University of Pennsylvania, 1972, pp. 28-31.

[10] A. Ishizaka and A. Labib, "Review of the main developments in the analytic hierarchy process," Expert Systems with Applications, vol. 38, no. 11, pp. 14336-14345, 2011.

[11] C. H. Cheng, K. L. Yang, and C. L. Hwang, "Evaluating attack helicopters by AHP based on linguistic variable weight," European Journal of Operational Research, vol. 116, no. 2, pp. 423-435, 1999.

[12] D. Ben-Arieh and T. Easton, "Multi-criteria group consensus under linear cost opinion elasticity," Decision Support Systems, vol. 43, no. 3, pp. 713-721, 2007.

[13] D. Ben-Arieh, T. Easton, and B. Evans, "Minimum cost consensus with quadratic cost functions," IEEE Transactions on Systems,
Man and Cybernetics, Part A: Systems and Humans, vol. 39, no. 1, pp. 210-217, 2009.

[14] G. Zhang, Y. Dong, Y. Xu, and H. Li, "Minimum-cost consensus models under aggregation operators," IEEE Transactions on Systems, Man and Cybernetics, Part A: Systems and Humans, vol. 41, no. 6, pp. 1253-1261, 2011.

[15] D. Zhang, J. Zhang, K. K. Lai, and Y. Lu, "An novel approach to supplier selection based on vague sets group decision," Expert Systems with Applications, vol. 36, no. 5, pp. 9557-9563, 2009.

[16] A. Lu and W. Ng, "Vague sets or intuitionistic fuzzy sets for handling vague data: which one is better?" in Proc. Conceptual Modeling-ER 2005, 2005, pp. 401-416.

[17] W. L. Gau and D. J. Buehrer, "Vague sets," IEEE Transactions on Systems, Man, and Cybernetics, vol. 23, no. 2, pp. 610-614, 1993.

[18] F. Hasson, S. Keeney, and H. McKenna, "Research guidelines for the Delphi survey technique," Journal of Advanced Nursing, vol. 32, no. 4, pp. 1008-1015, 2000.

[19] Y. M. Wang and T. M. Elhag, "An approach to avoiding rank reversal in AHP," Decision Support Systems, vol. 42, no. 3, pp. 1474-1480, 2006.

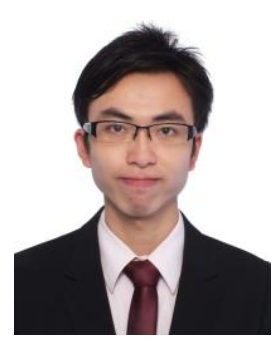

P. K. Kwok received the B.Eng. degree in Logistics Engineering and Supply Chain Management from the University of Hong Kong, HK in 2013. He is currently working towards the MPhil degree at the Department of Industrial and Manufacturing Systems Engineering, University of Hong Kong.

His research interests include multi-criteria decision making, group decision making and transportation planning.

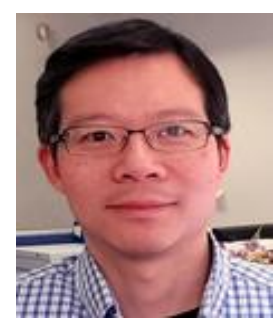

Henry Y. K. Lau is an Associate Professor in the Department of Industrial and Manufacturing Systems Engineering, The University of Hong Kong. Henry graduated from the University of Oxford with a BA Degrees in Engineering Science and a DPhil in Robotics. Prior to joining The University of Hong Kong, he has been working in industry for many years as a Systems Engineer and Section Manager at the UK Atomic Energy Authority (UKAEA) and AEA Technology plc., working on projects involving bespoke tele-robotics systems and advanced automation systems for the nuclear industry in decommissioning and waste management. While working in England, Henry was a Croucher Foundation Research Fellow at the University of Oxford Robotics Research Group, and a visiting lecturer at Brasenose College teaching Engineering Science. Henry's research interest includes artificial intelligence, in particular in artificial immune systems (AIS), intelligent automation for material handling, virtual and augmented reality systems. 